\title{
DIGITAL TWIN FOR INDOOR DISASTER IN SMART CITY: A SYSTEMATIC REVIEW
}

\author{
Sarah Shaharuddin ${ }^{1 \& 2}$, Khairul Nizam Abdul Maulud ${ }^{1 \& 3^{*}}$, Syed Ahmad Fadhli Syed Abdul Rahman ${ }^{4}$, Adi Irfan Che Ani ${ }^{5}$ \\ ${ }^{1}$ Earth Observation Centre, Institute of Climate Change (IPI), Universiti Kebangsaan Malaysia, 43600 UKM, Bangi, Selangor, \\ Malaysia. \\ ${ }^{2}$ Department of Survey and Mapping Pahang, 25050 Kuantan Pahang, Malaysia. \\ ${ }^{3}$ Department of Civil Engineering, Faculty of Engineering \& Built Environment, Universiti Kebangsaan Malaysia, 43600 UKM \\ Bangi, Selangor, Malaysia. \\ ${ }^{4}$ Cadastral Division, Department of Survey and Mapping Malaysia, 50578 Kuala Lumpur, Malaysia. \\ ${ }^{5}$ Department of Architecture and Built Environment, Faculty of Engineering and Built Environment, Universiti Kebangsaan \\ Malaysia, Bangi 43600, Selangor, Malaysia \\ P111119@siswa.ukm.edu.my, sara87an@gmail.com, knam@ukm.edu.my, syedfadhli@jupem.gov.my, adiirfan@ukm.edu.my
}

Commission 4, WG 7

KEY WORDS: Smart City, Digital Twin, Building Information Modelling (BIM), Systematic Review, Disaster Management, Indoor Disaster

\begin{abstract}
Technology has advanced and progressed tremendously, and the term city is being elevated to a new level where the smart city has been introduced globally. Recent developments in the concept of smart city have led to a renewed interest in Digital Twin. Using precise Building Information Modelling (BIM) consolidated with big data and sensors, several attempts have been made to establish digital twin smart cities. In recent years, several researchers have sought to determine the capability of smart city and digital twin for various taxonomies such as development and urban planning purposes, built environment, manufacturing, environmental, disaster management, and healthcare. Despite being beneficial in many disciplines, especially in manufacturing, built environment, and urban planning, these existing studies have shown a lack of aspect in terms of emergency or disaster-related as opposed to the elements mentioned above. This is because the researcher has not treated emergencies or disasters in much detail. Therefore, an extensive review on smart city, digital twin, BIM and disaster management and technology that revolves around these terms were summarised. In general, 39 articles from prominent multidisciplinary databases were retrieved over the last two decades based on the suggested PRISMA workflow. These final articles were analysed and categorised into four themes based on the research content, gist, and keywords. Based on the review of 39 articles related to smart city, digital twin and BIM, a workflow for the smart city digital twin and the conceptual framework for indoor disaster management was proposed accordingly. The establishment of smart city digital twins solely for an indoor emergency can be beneficial to urbanites, and it could provide numerous benefits for enhanced situation assessment, decision making, coordination, and resource allocation.
\end{abstract}

\section{INTRODUCTION}

The city is known as a melting pot for all people from all walks of life. Since then, the world has been rapidly urbanising, with urban population outnumbering rural population in 2008, and this has marked the beginning of a new 'urban millennium,' with twothirds of the world's population predicted to live in the cities by 2050 (UN-Habitat, 2015). With more than half of humanity living in cities and the increasing number of city dwellers surging every year, it is apparent that urban regions are projected to contribute to economic growth. As technology has advanced and progressed as a result of the invention and advancement of technology, the term city is being elevated to a new height where the smart city has been introduced globally. In general, there is no customary accepted definition for smart city, and this term was introduced as early as in the 1990s (Ramaprasad et al., 2017). Some has defined smart city as an urban centre for the future that revolves around a safe, secure environment and efficient utilities integrated with computerised system (Hall et al., 2000) while others envisaged it as the capacity to achieve positive outcomes despite the complexity of human activities while also continually adjusting to unprecedented human actions (Mohammadi \& Taylor, 2017).
Recent developments and advancements in the concept of smart cities have triggered an interest in the digital twin. (White et al., 2021) described digital twin as a digital representation of a physical process, human, place, system, or instrument. Initially, digital twins were constructed to refine manufacturing processes by simulating individual components with great accuracy. However, several attempts have been made using precise Building Information Modelling (BIM) consolidated with big data and sensors to establish digital twin for smart cities (Dembski et al., 2020a; Mohammadi \& Taylor, 2017), According to an article published online by (GW Prime, n.d.) Malaysia is spearheading digital twinning in the construction of the Pan Borneo Highway which has resulted in massive cost savings. It is also stated that Pan Borneo Highway is the first highway project in Malaysia to use Reality Modelling, BIM, and Geographical Information System (GIS) information to deliver Digital Twin Model. In line with the Digital twin spirits to enable data analysis and system monitoring to prevent problems from occurring, reduce downtime, and even prepare for the future using simulations (White et al., 2021), the use of digital twins solution throughout the projects has enabled analytics and immersive visualisation for supporting decision making and at the same optimising cost, operations and maintenance. 
In recent years, several researchers have sought to determine the capability of smart city and digital twin for various taxonomies such as development and urban planning purposes, built environment, manufacturing, environmental, disaster management, and healthcare. Despite being beneficial in many disciplines, especially in manufacturing, built environment and urban planning, these existing studies have shown a lack of aspect in terms of emergency or disaster-related as opposed to the elements mentioned above. This is because the researcher has not treated emergencies or disasters in much detail. This is also highlighted by (Doğan et al., 2021). Few scholars have discussed disaster, but such expositions are unsatisfactory because less attention is given to indoor risk and disaster than outdoor hazards.

Correspondingly, this paper attempts to seek the prospects of smart city digital twin as a whole and narrow it to indoor disaster management based on the previous research accordingly. An extensive review on smart city, digital twin, BIM and disaster management and technology that revolves around these terms were summarised. In general, 39 articles from prominent multidisciplinary databases were retrieved over the last two decades. The structure of this paper is segregated into few parts: Section 1 is the preamble of smart city, digital twin and the branches of knowledge commonly associated with these terms followed by methods applied for search strategy in Section 2; summary of the results and findings based on the literature search in Section 3; Section 4 discussed future research potential and barriers and Section 5 concludes the paper entirely.

\section{METHODS}

The idea and concept related to the smart city, digital twin and BIM are apparent with a bundle of research associated with these terms and consistent with the advancement of the Internet of Things (IoT), Big Data, Wireless Network Sensor (WNS). The literature search for each concept, if to be carried out individually, will produce countless results. However, the combination of these keywords would produce smaller search results. The literature search for this review paper adopted Preferred Reporting Items for Systematic Reviews and MetaAnalyses (PRISMA) guidelines (Pahlevan Sharif et al., 2019). PRISMA contains a 27 item checklist and a flow diagram that help systematic reviewers to report the findings accurately, clearly and exhaustively to other users (Page et al., 2021). The whole process of searching, identifying, screening, checking, and finalising the information for this review is as the PRISMA flow diagram.

\subsection{Data Identification}

The search queries for this paper were constructed based on the related keywords, combined using a suitable Boolean operator, and then carried out on the major academic search platform. For this purpose, four main strings were outlined, namely i) "smart city, digital twin, disaster"; ii) "smart city, digital twin, BIM"; iii) "smart city, digital twin, BIM, disaster" and iv) "smart city and digital twin". To retrieve the desired articles, prominent academic search platforms Web of Science (WoS), Scopus, Science Direct and Industry, Electrical and Electronics Engineers (IEEE) were utilised. For each of these databases, different search queries were used to conform to the database search requirement. However, the inclusion and exclusion criteria used for filtration were set equally: search must include 2000 to 2021 and exclude non-English articles. The year range was set to start from 2000 since the smart city, digital twin, and BIM have just progressed. Table 1 summarises the search queries and databases used for data identification.

\subsection{Data Screening}

Following the search queries and criteria, a total of 126 articles were retrieved. Before data screening was performed, the resulted articles were identified for duplication, and 17 articles were found to be redundant among the four search databases. These similar articles were then removed, and only 109 articles remained. These 109 articles were screened by reviewing the relevancy of the abstract per the intention of this review paper and 59 articles were excluded due to their irrelevancy. That makes 50 articles eligible for retrieving, and once the process was over, 9 articles could not be retrieved, and 41 further articles were assessed for eligibility. Further screening was executed and there was 2 book chapter hence it was excluded. The final article left for to be synthesised and analysed was 39 . The whole process was achieved based on the PRISMA flow diagram as per Figure 1 and it was simplified as per Figure 2 with additional information on the platform, string and criteria applied for literature search.

\begin{tabular}{|c|c|c|}
\hline Search Platform & Search String & $\begin{array}{c}\text { Search } \\
\text { Criteria }\end{array}$ \\
\hline WoS & $\begin{array}{c}\mathrm{ALL}=(\text { smart city AND } \\
\text { digital twin AND } \\
\text { Disaster*) } \\
\& \\
\text { ALL }=(\text { smart city AND } \\
\text { digital twin AND BIM) }\end{array}$ & $\begin{array}{c}\text { Include } \\
\text { Year Range } \\
2000 \text { to } 2021\end{array}$ \\
\hline Scopus & $\begin{array}{l}\text { TITLE-ABS-KEY(smart } \\
\text { city AND digital twin } \\
\text { AND Disaster*) } \\
\& \\
\text { TITLE-ABS-KEY (smart } \\
\text { AND city AND digital } \\
\text { AND twin AND BIM) }\end{array}$ & $\begin{array}{l}\text { Exclude } \\
\text { Non-English } \\
\text { Article }\end{array}$ \\
\hline Science Direct & $\begin{array}{l}\text { "smart city" AND "digital } \\
\text { twin" AND BIM AND } \\
\text { Disaster* }\end{array}$ & $\begin{array}{c}\text { Include } \\
\text { Year Range } \\
2000 \text { to } 2021\end{array}$ \\
\hline IEEE & $\begin{array}{c}\text { ALL METADATA: } \\
\text { smart city AND digital } \\
\text { twin } \\
\& \\
\text { smart city AND disaster }\end{array}$ & $\begin{array}{l}\text { Exclude } \\
\text { Non-English } \\
\text { Article }\end{array}$ \\
\hline
\end{tabular}

Table 1. List of search queries, search platforms, search criteria. 


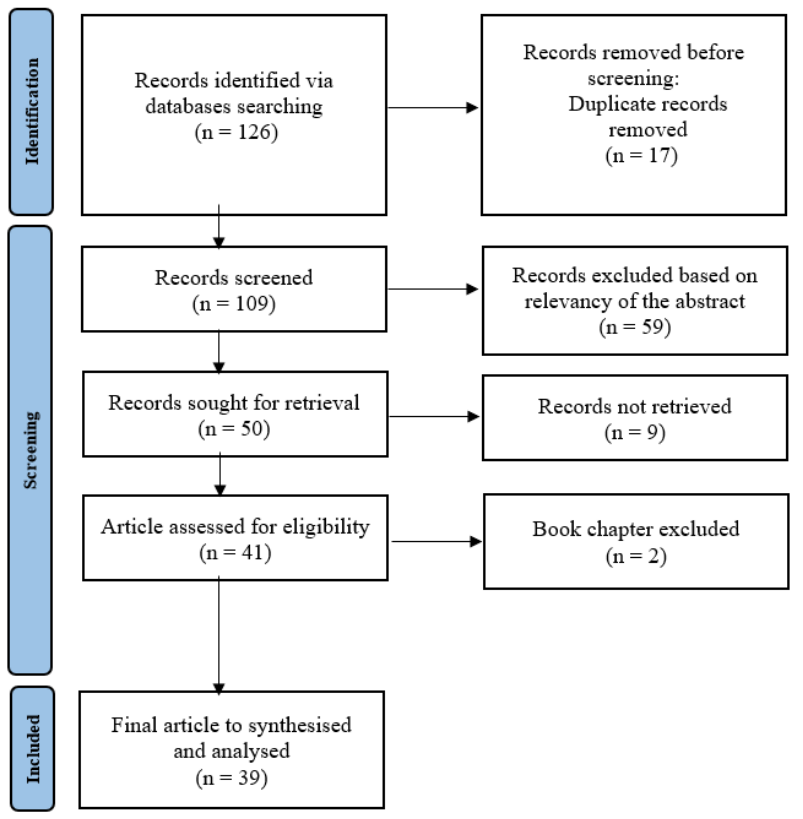

Figure 1. PRISMA flow diagram for the literature search.

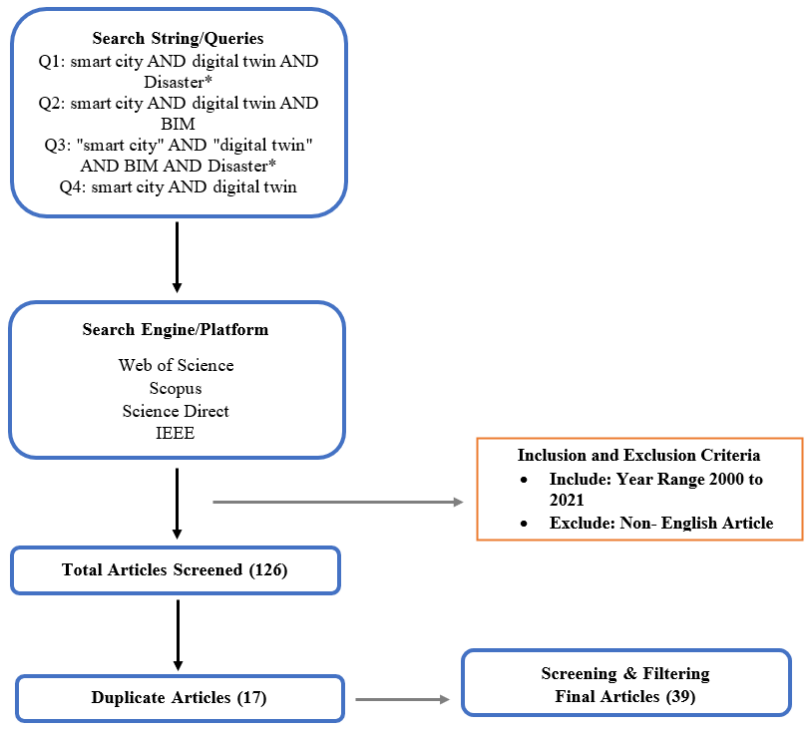

Figure 2. Simplified diagram with additional information.

\section{RESULTS}

The review process started by classifying the final articles. Generally, these articles can be segregated into two types of publication; conference proceedings and journal articles. Figure 2 shows an overview of the information. According to Journal Citation Report, the related journal article referred for this systematic review can be classified into the following quartile as per figure 3. Overall, there is total 24 articles where 8 articles were rank as Q1, 11 articles as Q2, 4 articles as Q3 and only 1 were classified as Q4. In a way it shows that the reliability of this review as it refers to established and reputable journals. The overall thematic classifications and their sub-theme applications from the articles are listed in Table 2. To further understand the research idea and direction, each of these thematic classifications was elaborated in this section.

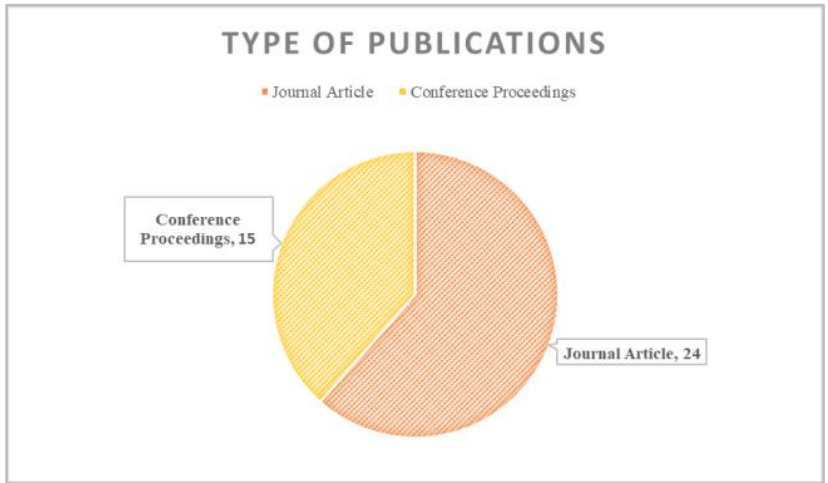

Figure 2. An Overview of Type of Publication.

\subsection{Theme: Smart City}

In the past two decades, the idea of smart city establishment has become increasingly important for sustainable and resilient cities. It should uphold the spirit of for a city to be "smart", technical innovations and ideas must be citizen-centric and must be able to enhance the quality of life of all its inhabitants rather than focusing on the economy solely (Loo \& Tang, 2019).

\section{JOURNAL ARTICLE BREAKDOWN}

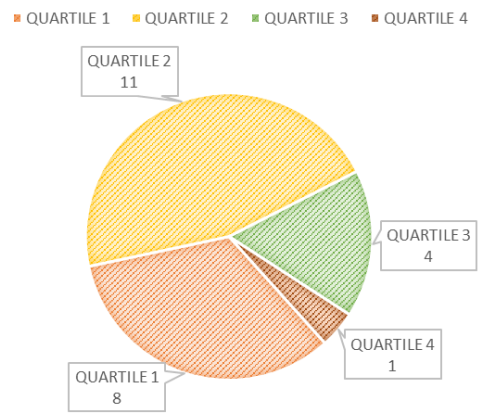

Figure 2. An Overview of Journal Article Breakdown

\begin{tabular}{|c|l|}
\hline Themes & \multicolumn{1}{|c|}{ Sub-themes (Application) } \\
\hline Smart City & - Smart Living \\
& - Smart Governance \\
& - Urban Planning \& Forecasting \\
& - Transportation \\
& - Disaster Management \& \\
& Situational Awareness \\
Digital Twin & - Definition \\
& - Built Environment \\
& - Technology \& Data Enabler \\
& - Health \& Manufacturing \\
& - Methodological Framework \\
BIM & - Disaster Management \\
& - Data conversion \\
& - Smart Construction \\
Technology Enabler & - Disaster Management \\
\& Cyber Security & - IoT \\
& - BG \\
& - Blockchain \\
& - Data Centre \\
& - Cyber-Physical System \\
\hline
\end{tabular}

Table 2. Thematic and Sub Thematic Classification. 
Numerous efforts have been made all over the world to realise the concept of smart city. For instance, a project called bIoTope involving three cities in the European Union: Helsinki, Lyon and Brussels applied an open communication and data standard ecosystem to support efficient smart city service integration.

Each of these cities has been assigned with different proof of concept (PoC), in Helsinki the independent electronic vehicle (EV) charging station allows relevant stakeholders to easily integrate their service for the citizen while in Lyon a smart watering system that can self-adapt to climate change due to the heatwave and finally in Brussels a PoC that focuses on the safety of the children when they travel to and from school (Javed et al., 2020). This is quite similar to the efforts of Takamatsu City in Japan; the first organisation in Japan to use the FIWARE platform for disaster management- visualisation of water level in real-time and tourism -tracking the rental bicycle data (Ishii \& Yamanaka, 2018). In addition to the bIoTope project, Helsinki is widely known for its fast adaption of the smart city concept since the 1980s and this is parallel with (Ruohomaki et al., 2018) findings on mySMARTLife project that acts as a rich, real-time and open data-sharing platform and soon to be upgraded into Digital Twin with focuses into Kalasatama District as a pilot. Meanwhile in China, (Geng \& Du, 2021) has proposed a technical framework consisting of basic technology with the support of additional technology such as blockchain to create smart community governance that intends to improve some inadequacy in the governance ruling approach. Due to the rapid advancement of technology, CitiSim; a smart city ecosystem project jointly anchored by Spain and Romania plans to extend the concept into digital twin using Unity Game Engine (Villanueva et al., 2020) and the same idea has been implemented by (Clark et al., 2020) using customise Unity to model a smart city.

Among the characteristics of a smart city is the capability to provide smart living and a smart environment with the whole automated process (Ahad et al., 2020). In Taiwan, a case study for the underground garage was conducted to monitor and detect hazardous gas produced by the vehicles, which will automatically trigger smart system ventilation if the situation is found to be endangering (Lin \& Cheung, 2020) and (Zakharov et al., 2019) has also proposed the automated approach to optimise building temperature based on the observed temperature information. As per the environment aspect, a project called Greenhouse Industry 4.0 (GHI4.0) was established in Denmark for the commercial greenhouse production process to become sustainable and convertible to other energy users (Anthony Howard et al., 2020). Similarly, a heatwave exposure in Columbus, Georgia was tackled proactively using computer vision algorithms combine with citizen activities and interaction, consequently assist in decision making (Mavrokapnidis et al., 2021). Meanwhile, (Shah et al., 2019) has come out with novel architecture for disaster resilient smart city using big data analytics and IoT that can be used real-time and offline.

Apart from the technical inventions, smart cities go beyond that and could even assist people with disabilities where this idea was described by (Svelec et al., 2020) and also the integration of BIM with IoT to detection emotion and level of comfort of a student in universities campus (Zaballos et al., 2020).

Time is the essence and the most critical element in any disaster management in reducing casualties and property damages. (Fan et al., 2021; Ford \& Wolf, 2020) have proposed the development of a smart city with a digital twin to improve the current disaster management and therefore provide efficient and smart disaster management. On the other hand (Asimakopoulou \& Bessis, 2011; Fan, Jiang, et al., 2020) have suggested a probability to integrate crowdsourcing and social sensing concepts into the disaster workflow to facilitate decision-makers with more accurate data. In Korea, (Park, Park, et al., 2018) has introduced Smart IoT Based Building and Town Disaster Management System (BTDMS) using a small test-bed system board to accommodate fire accidents in buildings. (Doğan et al., 2021) has also come out with Digital Twin Disaster Management System (DT-DMS), in which the system simulates a previous earthquake incident in Istanbul. The system tries to follow the digital twin approach; however, it does not conform to the concept as the data was not real-time but pre-historic data.

\subsection{Theme: Digital Twin}

Digital twins have traditionally been employed in the manufacturing industry, but they are beginning to find new applications in other fields of research and technology (White et al., 2021). Since the trends of research featuring digital twin is increasing it is vital to understand the definition fully. (Sepasgozar, 2021) has discerned the difference between the digital twin and digital shadow. Likewise, (Fuller et al., 2020) has clear out the misconceptions of the digital model, digital shadow and digital twin. The author also highlighted typical applications normally associated with digital twins such as smart cities, manufacturing and healthcare. (Erol et al., 2020) has also pointed out the same application perspective and predicts that the maturity level of this technology will increase and the technology will expand in other taxonomy such as piloting, engineering and medical education. To delve further into healthcare aspects, (Laamarti et al., 2020) has presented the use of digital twin for long-term personal health monitoring thus creating a wellinformed medical status of citizen.

Meanwhile, the increasing demand for using the digital twin concept for urban planning is evident as featured in (Dembski et al., 2020b; B. Kim et al., 2021; Mohammadi \& Taylor, 2017; White et al., 2021). There is also an attempt to heighten digital twin urban planning towards urban intelligence using multidisciplinary analysis (MDA) that allows interaction among cross-discipline that can support policymakers (Castelli et al., 2019). Some authors have been interested in establishing an appropriate methodological framework to bridge the gap between the physical and virtual city (Ivanov et al., 2020; PetrovaAntonova \& Ilieva, 2019).

With regards to the previous research work (smart city section), the use of Unity Game Engine in supporting the development of the smart city and digital twin is obvious. (Lee et al., 2020) employs the same engine to allow detection, reconstruction, and visualisation of movable dynamic data for digital twin cities.

Turning now to the experimental evidence on the advantages of leveraging crowdsourcing data, (J. Kim et al., 2019) has successfully conducted a case study in Houston, Texas using pre, during and post crowdsourced information with multimodal sensing data and an interactive computer-aided-virtual environment that helps decision making. A different approach (Zheng, 2021) was used to design a digital twin for urban rail transit without crowdsourced data instead; it involves 3D Modelling, Virtual Reality interaction and ubiquitous network. It is also worth noting that there was an effort from (Fan, Farahmend, et al., 2020) to test a theoretical framework on integrating human sentiment with infrastructure condition assessment, preceding any disastrous events using the smart city digital twin concept. 


\subsection{Theme: BIM}

According to (Zhu \& Wu, 2021), to develop a smart city and digital twin, the key building block is integrating BIM and Geographic Information System (GIS). Therefore, it is necessary to find a practical way for data conversion. The author also highlighted that conversion of Industry Foundation Classes (IFC) format to shapefile much easier using computer graphics technique. (M. Deng et al., 2021) concludes that BIM has contributed significantly in the Architecture, Engineering and Construction - Facilities Management (AEC-FM) industry with the capability to support the construction process, visualise the building elements or even provide an insight into the indoor environment. However, BIM is commonly associated with static data and does not have any real-time information (Alshammari et al., 2021; Liu et al., 2020) This is where BIM becomes useful with the integration of IoT technologies.

As the IoT technologies are widely progressing, the linking of BIM and IoT will achieve a cyber-physical system that will produce smart buildings (Alshammari et al., 2021) and in the same vein, (Liu et al., 2020) suggest that the combination of IoT and BIM with the customising algorithm will improve the indoor safety management of buildings. For that reason, it is important to prepare a cybersecurity layer on top of the rich data and (Alshammari et al., 2021) has proposed several recommendations to tackle the issue.

\subsection{Theme: Technology Enabler \& Cyber Security}

Core technology interventions such as artificial intelligence (AI), IoT, big data, blockchain and fifth-generation wireless systems (5G) have notably contributed to the smart city digital twin and BIM domain (Ahad et al., 2020; Alshammari et al., 2021; T. Deng et al., 2021). Specifically (Ahad et al., 2020) has listed twelve enabling technologies in smart cities and emphasise on the importance of security mechanism for the dynamic network and setting in a smart city environment as the traditional security does not fit in the equation. In (Alshammari et al., 2021) analysis of cybersecurity preparedness according to eight cities that are using the FIWARE platform in Europe, the author has pointed out that most of the cities failed to fulfil the criteria. A broader perspective has been adopted by (T. Deng et al., 2021) who presented an idea of digital twin composition that consists of infrastructure elements (technology-related), urban brain (intelligence hub) and the application layer (output). The basis of the framework is the strong foundation backs by advanced technology.

\section{DISCUSSION}

Deriving from the review of 39 articles related to smart city, digital twin, and BIM, these three themes are interconnected with each other and are indispensable for the development of smart city digital twin. In addition, a strong relationship between technology interventions with smart city, digital twin and BIM have been reported in the literature. Many researchers have sought to determine the advantages of digital twin and BIM in a smart city setting for major domains such as smart living (automated building temperature; emotion detection; people with disabilities; hazardous gas detection in a parking garage), smart governance (real-time water level detection for flood; tourism; blockchain technology to improve existing governance ruling); urban planning (citizen participatory before making a developmental decision; what if simulation; crowdsourcing and social sensing integration) and disaster management \& situational awareness (IoT utilisation for real-time situation; what if simulation; the relationship between human emotions and city facilities; earthquake simulation).

It is interesting to note that among 39 articles that have been reviewed, indoor disaster management with regards to the digital twin has been given a lack of attention. Insufficient real-time information and a complicated indoor navigation approach contribute less research related to indoor disasters than normal outdoor disasters. This is also stressed by (Liu et al., 2020) in the research and the author has proposed an indoor safety management system (ISMS) that utilise the use of IoT sensors and support vector machines (SVM). Time is the essence and the most critical element in any disaster management in reducing casualties and property damages. Efficient and smart disaster management is crucial to lessen the loss especially if it occurs indoors. (Park, Hoan Park, et al., 2018). mention that it can be confirmed that many of the times casualties are caused due to unclear evacuation routes (falling during the evacuation, unable to escape, and unknown etc.). This is strongly justified by (Mappedin, 2020) in which firefighters have an ideal response time of just $51 / 2$ minutes, which they try to reach in $90 \%$ of emergencies situation but if the situation involves indoor evacuation without any efficient navigational approach it might be hard to achieve.

\subsection{Proposed workflow and conceptual framework}

Future studies on the use of smart city and digital twin in a single platform are therefore recommended. The rationalisation in joining both concepts is to create a smart indoor disaster management system that allows what-if simulation and forecasting to assist and support decision making as suggested by (Ford \& Wolf, 2020). This section will briefly elaborate on the proposed workflow for the smart city digital twin and the conceptual framework for indoor disaster management. The proposed workflow will require data preparation that incorporates a 3D Building Model (BIM) of the building, installation of sensors for smoke detection and room temperature paired with additional information from external features such as demarcation, utility, and transportation. This combined information as per the smart city attribute will construct a complete dataset. This information and hardware need to be assembled accordingly and therefore will allow simulation on virtual digital twin settings as illustrated in Figure 4.

The proposed conceptual framework as per Figure 5 shows that to create a virtual copy of the physical building, the physical information must be sufficiently established with IoT technology to support real-time incidents. Consideration must be made to include the use of software to connect building and sensor information as well as software that is capable of doing simulations related to the disaster. 
3D BUILDING MODEL (BIM)

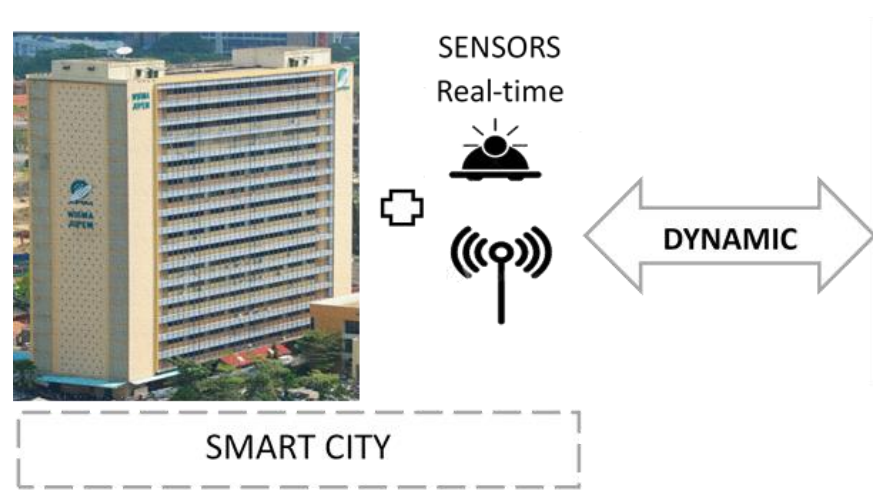

VIRTUAL REPLICATION OF BUILDING INTEGRATED WITH SENSORS

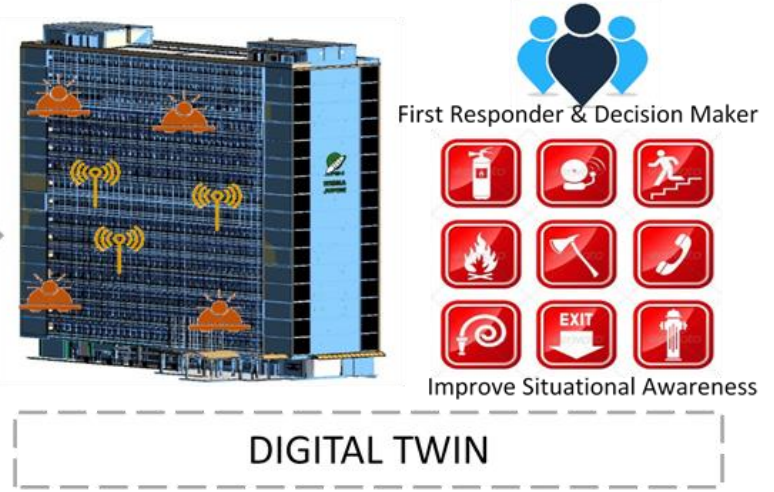

Figure 5. Proposed conceptual framework to create smart city digital twin for indoor hazard Source of building: Department of Survey and Mapping Malaysia

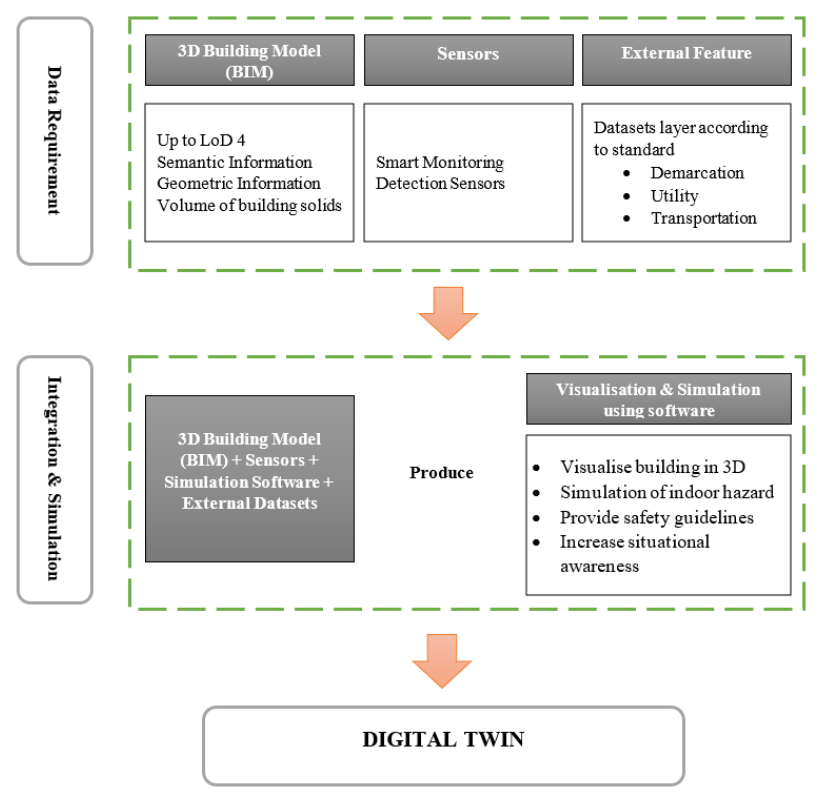

Figure 4. Proposed workflow to create smart city digital twin for indoor hazard.

\section{CONCLUSIONS}

This review was undertaken to explore the smart city, digital twin, and BIM domains and their association with indoor disaster management. For this purpose, a total of 39 articles related to the theme mentioned earlier was reviewed. The literature search of this information has shown that less research was done in the angle of indoor disaster with regards to smart city and digital twin. This might be due to the requirement of the digital twin that requires real-time virtual copy rather than static information. Nevertheless, new value-added knowledge such as data conversion, the use of technology enablers, the importance of data security was something that can be considered in the development of smart city digital twin indoor system later. Do note that the main hindrance of this paper is that the proposed workflow and conceptual framework were initiated based on the grounds of the literature search and might not represent the clear and actual picture of the actual practice industrially. To conclude, the establishment of smart city digital twins solely for an indoor emergency can be beneficial to urbanites and it could provide numerous benefits for enhanced situation assessment, decision making, coordination, and resource allocation

\section{ACKNOWLEDGEMENTS}

The authors would like to thank the Institute of Climate Change, Universiti Kebangsaan Malaysia and the Department of Survey and Mapping Malaysia for their assistance during the entire process of conducting this systematic review.

\section{FUNDING}

The authors would like to thank the Universiti Kebangsaan Malaysia, Malaysia, for Research University Grant, DIP-2021006.

\section{DISCLOSURE STATEMENT}

No potential conflict of interest was reported by the authors.

\section{REFERENCES}

(UN-Habitat, U. N. H. S. P. (2015). UN-HABITAT GLOBAL ACTIVITIES REPORT 2015.

Ahad, M. A., Paiva, S., Tripathi, G., \& Feroz, N. (2020). Enabling technologies and sustainable smart cities. Sustainable $\begin{array}{llll}\text { Cities and Society, } & \text { 61(May), } & 102301 .\end{array}$ https://doi.org/10.1016/j.scs.2020.102301

Alshammari, K., Beach, T., \& Rezgui, Y. (2021). Cybersecurity for digital twins in the built environment: current research and future directions. Journal of Information Technology in Construction, 26, 159-173. https://doi.org/10.36680/j.itcon.2021.010

Anthony Howard, D., Ma, Z., Mazanti Aaslyng, J., \& Norregaard Jorgensen, B. (2020). Data Architecture for Digital Twin of Commercial Greenhouse Production. 2020 RIVF International Conference on Computing and Communication Technologies (RIVF), 1-7. https://doi.org/10.1109/RIVF48685.2020.9140726

Asimakopoulou, E., \& Bessis, N. (2011). Buildings and Crowds: Forming Smart Cities for More Effective Disaster Management. 2011 Fifth International Conference on Innovative Mobile and 
Internet Services in Ubiquitous Computing, 229-234. https://doi.org/10.1109/IMIS.2011.129

Castelli, G., Tognola, G., Campana, E. F., Cesta, A., Diez, M., Padula, M., Ravazzani, P., Rinaldi, G., Savazzi, S., Spagnuolo, M., \& Strambini, L. (2019). Urban Intelligence: a Modular, Fully Integrated, and Evolving Model for Cities Digital Twinning. 2019 IEEE 16th International Conference on Smart Cities: Improving Quality of Life Using ICT \& IoT and AI (HONETICT), 033-037. https://doi.org/10.1109/HONET.2019.8907962

Clark, T., Brock, E., Wu, D., \& Liang, Y. (2020). Development of real-time smart city mapping utilizing game engines. 2020 International Symposium on Networks, Computers and Communications, $\quad$ ISNCC 2020. https://doi.org/10.1109/ISNCC49221.2020.9297248

Dembski, F., Wössner, U., Letzgus, M., Ruddat, M., \& Yamu, C. (2020a). Urban digital twins for smart cities and citizens: The case study of herrenberg, germany. Sustainability (Switzerland), 12(6), 1-17. https://doi.org/10.3390/su12062307

Dembski, F., Wössner, U., Letzgus, M., Ruddat, M., \& Yamu, C. (2020b). Urban Digital Twins for Smart Cities and Citizens: The Case Study of Herrenberg, Germany. Sustainability, 12(6), 2307. https://doi.org/10.3390/su12062307

Deng, M., Menassa, C. C., \& Kamat, V. R. (2021). From BIM to digital twins: a systematic review of the evolution of intelligent building representations in the AEC-FM industry. Journal of Information Technology in Construction, 26, 58-83. https://doi.org/10.36680/j.itcon.2021.005

Deng, T., Zhang, K., \& Shen, Z. J. (Max). (2021). A systematic review of a digital twin city: A new pattern of urban governance toward smart cities. Journal of Management Science and Engineering, $6(2)$ $125-134$.

https://doi.org/10.1016/j.jmse.2021.03.003

Doğan, Ö., Şahin, O., \& Karaarslan, E. (2021). Digital Twin Based Disaster Management System Proposal: DT-DMS. Journal of Emerging Computer Technologies, 1(2), 25-30.

Erol, T., Mendi, A. F., \& Dogan, D. (2020). Digital Transformation Revolution with Digital Twin Technology. 2020 4th International Symposium on Multidisciplinary Studies and

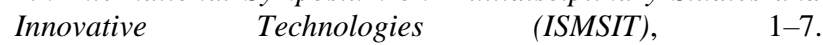
https://doi.org/10.1109/ISMSIT50672.2020.9254288

Fan, C., Farahmend, H., \& Mostafavi, A. (2020). Rethinking Infrastructure Resilience Assessment with Human Sentiment Reactions on Social Media in Disasters. https://doi.org/10.24251/HICSS.2020.205

Fan, C., Jiang, Y., \& Mostafavi, A. (2020). Social Sensing in Disaster City Digital Twin: Integrated Textual-Visual-Geo Framework for Situational Awareness during Built Environment Disruptions. Journal of Management in Engineering, 36(3), 04020002. https://doi.org/10.1061/(asce)me.1943-5479.0000745

Fan, C., Zhang, C., Yahja, A., \& Mostafavi, A. (2021). Disaster City Digital Twin: A vision for integrating artificial and human intelligence for disaster management. International Journal of Information Management, 56(March 2019), 102049. https://doi.org/10.1016/j.ijinfomgt.2019.102049
Ford, D. N., \& Wolf, C. M. (2020). Smart Cities with Digital Twin Systems for Disaster Management. Journal of Management in Engineering, 36(4), 04020027. https://doi.org/10.1061/(asce)me.1943-5479.0000779

Fuller, A., Fan, Z., Day, C., \& Barlow, C. (2020). Digital Twin: Enabling Technologies, Challenges and Open Research. IEEE Access, 8, 108952-108971. https://doi.org/10.1109/ACCESS.2020.2998358

Geng, Q., \& Du, Y. (2021). From Blockchain to Digital Twin Community: A Technical Framework for Smart Community Governance. 2021 International Conference on Public Management and Intelligent Society (PMIS), 277-280. https://doi.org/10.1109/PMIS52742.2021.00068

GW Prime. (n.d.). Use of Digital Twinning in Construction of Pan Borneo Highway Results in Massive Cost Savings. https://www.gwprime.geospatialworld.net/case-study/use-ofdigital-twinning-in-construction-of-pan-borneo-highwayresults-in-massive-cost-savings/

Hall, R. E., Bowerman, B., Braverman, J., Taylor, J., \& Todosow, H. (2000). The vision of a smart city. 2nd International Life ..., 28 .

Ishii, K., \& Yamanaka, A. (2018). Building a common smart city platform utilizing FIWARE (case study of Takamatsu City). NEC Technical Journal, 13(1), 28-31.

Ivanov, S., Nikolskaya, K., Radchenko, G., Sokolinsky, L., \& Zymbler, M. (2020). Digital Twin of City: Concept Overview. 2020 Global Smart Industry Conference (GloSIC), 20, 178-186. https://doi.org/10.1109/GloSIC50886.2020.9267879

Javed, A., Kubler, S., Malhi, A., Nurminen, A., Robert, J., \& Framling, K. (2020). bIoTope: Building an IoT Open Innovation Ecosystem for Smart Cities. IEEE Access, 8, 224318-224342. https://doi.org/10.1109/ACCESS.2020.3041326

Kim, B., Lim, C.-G., Lee, S.-H., \& Jung, Y.-J. (2021). A Study on the Population Distribution Prediction in Large City using Agent-Based Simulation. 2021 23rd International Conference on Advanced Communication Technology (ICACT), 68-71. https://doi.org/10.23919/ICACT51234.2021.9370797

Kim, J., Kim, H., \& Ham, Y. (2019). Mapping Local Vulnerabilities into a 3D City Model through Social Sensing and the CAVE System toward Digital Twin City. Computing in Civil Engineering 2019, 451-458. https://doi.org/10.1061/9780784482445.058

Laamarti, F., Badawi, H. F., Ding, Y., Arafsha, F., Hafidh, B., \& Saddik, A. El. (2020). An ISO/IEEE 11073 Standardized Digital Twin Framework for Health and Well-Being in Smart Cities. IEEE Access, 8, 105950-105961. https://doi.org/10.1109/ACCESS.2020.2999871

Lee, A., Kim, J., \& Jang, I. (2020). Movable Dynamic Data Detection and Visualization for Digital Twin City. 2020 IEEE International Conference on Consumer Electronics - Asia (ICCE-Asia), 1-2. https://doi.org/10.1109/ICCEAsia49877.2020.9277250

Lin, Y.-C., \& Cheung, W.-F. (2020). Developing WSN/BIM- 
Based Environmental Monitoring Management System for Parking Garages in Smart Cities. Journal of Management in Engineering, $36(3)$ 04020012

https://doi.org/10.1061/(asce)me.1943-5479.0000760

Liu, Z., Zhang, A., \& Wang, W. (2020). A Framework for an Indoor Safety Management System Based on Digital Twin. Sensors, 20(20), 5771. https://doi.org/10.3390/s20205771

Loo, B. P. Y., \& Tang, W. S. M. (2019). "Mapping” Smart Cities. Journal of Urban Technology, 26(2), 129-146. https://doi.org/10.1080/10630732.2019.1576467

Mappedin. (2020). 7 Ways Indoor Mapping Helps With Disaster Management. https://resources.mappedin.com/blog/indoormapping-improves-emergency-planning

Mavrokapnidis, D., Mohammadi, N., \& Taylor, J. (2021). Community Dynamics in Smart City Digital Twins: A Computer Vision-based Approach for Monitoring and Forecasting Collective Urban Hazard Exposure. Proceedings of the Annual Hawaii International Conference on System Sciences, 2020Jапиа, 1810-1818. https://doi.org/10.24251/HICSS.2021.220

Mohammadi, N., \& Taylor, J. E. (2017). Smart city digital twins. 2017 IEEE Symposium Series on Computational Intelligence (SSCI), 2018-Janua,

https://doi.org/10.1109/SSCI.2017.8285439

Page, M. J., McKenzie, J. E., Bossuyt, P. M., Boutron, I., Hoffmann, T. C., Mulrow, C. D., Shamseer, L., Tetzlaff, J. M., Akl, E. A., Brennan, S. E., Chou, R., Glanville, J., Grimshaw, J. M., Hróbjartsson, A., Lalu, M. M., Li, T., Loder, E. W., MayoWilson, E., McDonald, S., ... Moher, D. (2021). The PRISMA 2020 statement: an updated guideline for reporting systematic reviews. $B M J, \mathrm{n} 71$. https://doi.org/10.1136/bmj.n71

Pahlevan Sharif, S., Mura, P., \& Wijesinghe, S. N. R. (2019). Systematic Reviews in Asia: Introducing the "PRISMA" Protocol to Tourism and Hospitality Scholars (pp. 13-33). https://doi.org/10.1007/978-981-13-2463-5_2

Park, S., Hoan Park, S., Won Park, L., Park, S., Lee, S., Lee, T., Hyeon Lee, S., Jang, H., Min Kim, S., Chang, H., \& Park, S. (2018). Design and Implementation of a Smart IoT Based Building and Town Disaster Management System in Smart City Infrastructure. https://doi.org/10.3390/app8112239

Park, S., Park, S., Park, L., Park, S., Lee, S., Lee, T., Lee, S., Jang, H., Kim, S., Chang, H., \& Park, S. (2018). Design and Implementation of a Smart IoT Based Building and Town Disaster Management System in Smart City Infrastructure. $\begin{array}{llll}\text { Applied } & \text { Sciences, } & \text { 8(11), }\end{array}$ https://doi.org/10.3390/app8112239

Petrova-Antonova, D., \& Ilieva, S. (2019). Methodological Framework for Digital Transition and Performance Assessment of Smart Cities. 2019 4th International Conference on Smart and Sustainable Technologies (SpliTech), 1-6. https://doi.org/10.23919/SpliTech.2019.8783170

Ramaprasad, A., Sánchez-Ortiz, A., \& Syn, T. (2017). A Unified Definition of a Smart City. International Conference on Electronic Government. https://doi.org/10.1007/978-3-31964677-0_2
Ruohomaki, T., Airaksinen, E., Huuska, P., Kesaniemi, O., Martikka, M., \& Suomisto, J. (2018). Smart City Platform Enabling Digital Twin. 2018 International Conference on Intelligent Systems (IS), $0, \quad 155-161$ https://doi.org/10.1109/IS.2018.8710517

Sepasgozar, S. M. E. (2021). Differentiating Digital Twin from Digital Shadow: Elucidating a Paradigm Shift to Expedite a Smart, Sustainable Built Environment. Buildings, 11(4), 151 https://doi.org/10.3390/buildings11040151

Shah, S. A., Seker, D. Z., Rathore, M. M., Hameed, S., Ben Yahia, S., \& Draheim, D. (2019). Towards Disaster Resilient Smart Cities: Can Internet of Things and Big Data Analytics Be the Game Changers? IEEE Access, 7, 91885-91903. https://doi.org/10.1109/ACCESS.2019.2928233

Svelec, D., Bjelcic, N., \& Blazekovic, M. (2020). Smart cities as an opportunity and challenge for people with disabilities. 2020 $43 r d$ International Convention on Information, Communication and Electronic Technology, MIPRO 2020 - Proceedings, 456461. https://doi.org/10.23919/MIPRO48935.2020.9245183

Villanueva, F. J., Acena, O., Dorado, J., Cantarero, R., Bermejo, J. F., \& Rubio, A. (2020). On building support of digital twin concept for smart spaces. 2020 IEEE International Conference on Human-Machine Systems (ICHMS), 1-4. https://doi.org/10.1109/ICHMS49158.2020.9209384

White, G., Zink, A., Codecá, L., \& Clarke, S. (2021). A digital twin smart city for citizen feedback. Cities, 110, 103064. https://doi.org/10.1016/j.cities.2020.103064

Zaballos, A., Briones, A., Massa, A., Centelles, P., \& Caballero, V. (2020). A Smart Campus' Digital Twin for Sustainable Comfort Monitoring. Sustainability, 12(21), 9196. https://doi.org/10.3390/su12219196

Zakharov, A., Romazanov, A., Shirokikh, A., \& Zakharova, I. (2019). Intellectual Data Analysis System of Building Temperature Mode Monitoring. Proceedings - 2019 International Russian Automation Conference, RusAutoCon 2019 ,

https://doi.org/10.1109/RUSAUTOCON.2019.8867611

Zhu, J., \& Wu, P. (2021). Towards Effective BIM/GIS Data Integration for Smart City by Integrating Computer Graphics Technique. Remote Sensing, 13(10), 1889. https://doi.org/10.3390/rs13101889 